\title{
Influence of endoscopic submucosal dissection on additional gastric resections
}

\author{
Noboru Kawata $\cdot$ Naomi Kakushima $\cdot$ Masanori Tokunaga $\cdot$ Masaki Tanaka $\cdot$ Hiroaki Sawai \\ Kohei Takizawa $\cdot$ Kenichiro Imai $\cdot$ Kinichi Hotta $\cdot$ Yuichiro Yamaguchi $\cdot$ Hiroyuki Matsubayashi · \\ Yutaka Tanizawa $\cdot$ Etsuro Bando $\cdot$ Taiichi Kawamura $\cdot$ Masanori Terashima $\cdot$ Hiroyuki Ono
}

Received: 30 January 2014/ Accepted: 10 April 2014/Published online: 3 May 2014

(C) The International Gastric Cancer Association and The Japanese Gastric Cancer Association 2014

\begin{abstract}
Background Widespread application of endoscopic submucosal dissection (ESD) for early gastric cancer (EGC) results in noncurative resection in some patients. The influence of preceding ESD on additional gastric resections has not been completely evaluated.

Methods Endoscopic, surgical, and pathological records of 255 patients who underwent additional gastrectomy after noncurative ESD at a single prefectural cancer center from September 2002 to December 2010 were reviewed. The estimated gastric resection based on endoscopic images before ESD was compared with the actual gastric resection performed after ESD.

Results Altered gastric resection was performed in 4 $(1.6 \%)$ of the 255 patients. In 3 patients, total gastrectomy was performed instead of distal gastrectomy; in 1 patient, distal gastrectomy was performed instead of pylorus-preserving gastrectomy because of an insufficient distance from the cardia or pylorus caused by contraction of the ESD scar. Standard gastrectomy including total or distal gastrectomy with D2 lymph node dissection was performed in 33 patients because of deep submucosal invasion with
\end{abstract}

N. Kawata · N. Kakushima ( $₫) \cdot$ M. Tanaka $\cdot$ H. Sawai .

K. Takizawa $\cdot$ K. Imai $\cdot$ K. Hotta $\cdot$ Y. Yamaguchi ·

H. Matsubayashi · H. Ono

Division of Endoscopy, Shizuoka Cancer Center,

1007 Shimonagakubo, Nagaizumi, Suntougun,

Shizuoka 4118777, Japan

e-mail: kakushin-tky@umin.ac.jp

M. Tokunaga $\cdot$ Y. Tanizawa $\cdot$ E. Bando - T. Kawamura $~$

M. Terashima

Division of Gastric Surgery, Shizuoka Cancer Center,

Shizuoka, Japan positive/indefinite vertical margins. The final pathology revealed pT2 or deeper in 10 patients.

Conclusions In conclusion, $98.4 \%$ patients underwent the scheduled gastric resection before ESD, and the preceding gastric ESD had almost no influence on changing the gastric resection of the additional surgery. Although rare, the preceding ESD may necessitate alterations in gastric resection to widen the surgical area because of contraction of ESD scar for lesions near the cardia or pylorus.

Mini abstract A retrospective study of additional gastrectomy after noncurative ESD showed that the preceding ESD had almost no influence on changing the gastric resection of the additional surgery.

Keywords Endoscopic submucosal dissection - Early gastric cancer - Total gastrectomy · Distal gastrectomy · Proximal gastrectomy

\section{Introduction}

Patients with early gastric cancer (EGC) with negligible risk of lymph node metastasis are good candidates for endoscopic resection [1, 2]. Because of the widespread use of endoscopic submucosal dissection (ESD), many patients diagnosed with EGC have been successfully treated by ESD with curative intent [3-6]. EGC lesions indicated for endoscopic resection are defined by size, histology, and estimated depth [7]. However, because an accurate pathological diagnosis is possible only after total resection of the lesion, some lesions may be judged to have undergone noncurative resection on the basis of the risk of lymph node metastasis. Therefore, lesions presenting with pathological risk factors for metastasis, such as lymphovascular 
infiltration, deep submucosal invasion, and positive surgical margins, should undergo gastrectomy with lymph node dissection [8-10].

The standard surgery for gastric cancer involves resection of at least two-thirds of the stomach with D2 lymph node dissection [7]. For cT1cN0 tumors, modified gastric resections such as pylorus-preserving or proximal gastrectomy are becoming more common in Japan because of the lesser extent of lymph node dissection [11].

ESD allows for en bloc resection with sufficient tumornegative margins, even for large EGC lesions; therefore, the artificial ulcer scars created by ESD may cause fibrotic contraction over a larger area $[12,13]$. Although some studies have reported that laparoscopic surgery after noncurative ESD is a safe and feasible procedure [14, 15], no reports about the influence of ESD on additional gastric resections exist. Therefore, this study aimed to clarify the influence of preceding ESD on additional gastric resections among patients who failed to achieve curative ESD.

\section{Patients and methods}

Among all patients treated by ESD from September 2002 to December 2010 at Shizuoka Cancer Center Hospital (Shizuoka, Japan), 255 patients with 261 lesions underwent additional gastrectomy because of noncurative resection. Endoscopic images obtained before ESD were retrospectively reviewed, and the appropriate extent of gastric resection was estimated for each lesion. Gastric resection was decided as in Table 1, according to the treatment guidelines for gastric cancer adopted by the Japanese Gastric Cancer Association in 2010 [7]. In our institution, pylorus-preserving gastrectomy was first introduced in 2008. Pathological and surgical patient records were reviewed, and lesion characteristics, reasons for noncurative ESD, and actual gastric resections performed were evaluated.

Table 1 Indication of gastric resections for early gastric cancer

\begin{tabular}{ll}
\hline Gastric resection & Indication \\
\hline $\begin{array}{l}\text { Total gastrectomy } \\
\text { Distal gastrectomy }\end{array}$ & $\begin{array}{c}\text { Proximal distance from the cardia is }<2 \mathrm{~cm} \\
\text { Proximal distance from the cardia is } 2 \mathrm{~cm} \text { or } \\
\text { more }\end{array}$ \\
$\begin{array}{c}\text { Pylorus-preserving } \\
\text { gastrectomy }\end{array}$ & $\begin{array}{c}\text { Lesions in the middle portion of the stomach } \\
\text { with al distance of at least } 4 \mathrm{~cm}\end{array}$ \\
$\begin{array}{c}\text { Proximal } \\
\text { gastrectomy }\end{array}$ & $\begin{array}{c}\text { Proximal lesions where more than half of the } \\
\text { distal stomach can be preserved }\end{array}$ \\
$\begin{array}{c}\text { Total remnant } \\
\text { gastrectomy }\end{array}$ & Lesions in a remnant stomach \\
\hline
\end{tabular}

From Japanese Gastric Cancer Association [7]
Absolute indication for endoscopic resection

differentiated-type adenocarcinoma, UL(-), $\mathrm{c}^{\top} \mathrm{T} 1 \mathrm{a}, \leq 2 \mathrm{~cm}$

\section{Expanded indication for endoscopic resection}

differentiated-type adenocarcinoma, $\mathrm{UL}(-), \mathrm{cT} 1 \mathrm{a},>2 \mathrm{~cm}$

differentiated-type adenocarcinoma, $\mathrm{UL}(+), \mathrm{cT} 1 \mathrm{a}, \leq 3 \mathrm{~cm}$

Undifferentiated-type adenocarcinoma, UL(-), cT1a, $\leq 2 \mathrm{~cm}$

Fig. 1 Indication criteria of early gastric cancer for endoscopic resection proposed by the Japanese Gastric Cancer Treatment Guidelines. $U L$ ulceration findings

\section{Evaluation of EGC before ESD}

Before ESD, all the patients were evaluated by esophagogastroduodenoscopy (GIF-H260; Olympus, Tokyo, Japan) with chromoendoscopy. For lesions suspected of submucosal invasion, additional endosonography was performed. A biopsy of the lesion was performed to diagnose the histological cancer type before ESD. Several biopsies around the estimated border of the lesion were performed to confirm areas with nonneoplastic mucosa. The lesions were categorized as absolute indication, expanded indication, and contraindication for ESD according to the criteria for endoscopic resection proposed by the treatment guidelines (Fig. 1) [7]. The treatment of all EGC patients was discussed at our institutional cancer board, which consists of endoscopists, gastroenterologists, and surgeons.

According to the Japanese Gastric Cancer Treatment Guidelines 2010 (ver. 3) [7], ESD was deemed to be curative when all the following conditions were fulfilled: (a) en bloc resection with margins free of cancer and no lymphovascular infiltration; (b) differentiated-type pT1a cancer without ulcerative findings; (c) a differentiated-type pT1a lesion, no larger than $3 \mathrm{~cm}$ in diameter, with ulcerative findings; (d) a differentiated-type pT1b lesion (SM1, invasion less than $500 \mu \mathrm{m}$ below the muscularis mucosa) no larger than $3 \mathrm{~cm}$ in diameter; and (e) an undifferentiated-type pT1a lesion no larger than $2 \mathrm{~cm}$ in diameter, without ulcerative findings. A resection that did not satisfy any of these criteria was considered to be noncurative. This retrospective study was approved by the ethics committee of Shizuoka Cancer Center Hospital (Approval No.: 24-J114-24-1-3).

\section{Results}

Demographic and lesion characteristics are summarized in Table 2. Nearly half $(122 ; 47 \%)$ of the 261 lesions in the 255 patients ( $81 \%$ male; median age, 69 years) were 
Table 2 Demographic and tumor characteristics of 261 lesions in 255 patients who underwent additional gastric resection after noncurative endoscopic submucosal dissection (ESD)

\begin{tabular}{|c|c|}
\hline \multicolumn{2}{|l|}{ Age } \\
\hline Median (range) & $69(37-89)$ \\
\hline \multicolumn{2}{|l|}{ Gender } \\
\hline Male/female & $206 / 49$ \\
\hline \multicolumn{2}{|l|}{ Location } \\
\hline Upper portion & $69(26 \%)$ \\
\hline Middle portion & $122(47 \%)$ \\
\hline Lower portion & $70(27 \%)$ \\
\hline \multicolumn{2}{|l|}{ Indication for endoscopic resection (ER) } \\
\hline Absolute & $97(37 \%)$ \\
\hline Expanded & $121(46 \%)$ \\
\hline Contraindicated & $43(17 \%)$ \\
\hline \multicolumn{2}{|l|}{ Reason for noncurative resection (with overlapping) } \\
\hline pT1b-(SM2) & $153(59 \%)$ \\
\hline pT1b-(SM1), $>3 \mathrm{~cm}$ & $31(12 \%)$ \\
\hline $\mathrm{UL}(+),>3 \mathrm{~cm}$ & $25(10 \%)$ \\
\hline Undifferentiated type, $>2 \mathrm{~cm}$ or UL (+) or pT1b & $17(7 \%)$ \\
\hline ly $(+)$ & $93(36 \%)$ \\
\hline $\mathrm{v}(+)$ & $49(19 \%)$ \\
\hline $\mathrm{HM}+$ or indefinite & $15(6 \%)$ \\
\hline $\mathrm{VM}+$ or indefinite & $55(21 \%)$ \\
\hline \multicolumn{2}{|l|}{ Time from ESD to surgery } \\
\hline Median, day (range) & $70(23-470)$ \\
\hline \multicolumn{2}{|l|}{ Surgical procedure } \\
\hline Open surgery & $236(93 \%)$ \\
\hline Laparoscopic surgery & $19(7 \%)$ \\
\hline \multicolumn{2}{|l|}{ Operation time, min } \\
\hline Mean, SD & $198( \pm 55)$ \\
\hline \multicolumn{2}{|l|}{ Intraoperative blood loss, ml } \\
\hline Mean, SD & $307( \pm 287)$ \\
\hline
\end{tabular}

$U L$ ulcerative findings, $l y$ lymph vessel infiltration, $v$ vascular infiltration, $H M+$ positive horizontal margin, $V M+$ positive vertical margin, $S D$ standard deviation

located in the middle portion of the stomach. Deep submucosal invasion was the most common reason leading to a judgment of noncurative ESD (153/261, $59 \%)$. Additional gastrectomy was performed at a median of 70 days after ESD. Most patients (236/255, 93 \%) underwent open surgery. Laparoscopy-assisted distal gastrectomy (DG) was performed in 14 patients, and laparoscopy-assisted pyloruspreserving gastrectomy (PPG) was performed in 5 patients. The mean operation time was $198 \mathrm{~min}$, and the mean intraoperative blood loss was $307 \mathrm{ml}$. Only one case of intraabdominal adhesion required partial resection of the mesocolon. This case had a perforation during the preceding ESD and was sealed using endoclips.

The estimated gastric resections before ESD and the resections actually performed are shown in Fig. 2. Among
164 patients in whom DG with D1+ lymph node dissection $(\mathrm{D} 1+)$ was the estimated gastric resection, the actual resection after ESD was DG with D1+ in 134, DG with D2 lymph node dissection (D2) in 26, total gastrectomy (TG) with D1+ in 3, and local resection in 1 . In the 3 patients, the lesions were located in the upper portion of the stomach, and the ulcer scar after ESD was near the cardia, with an insufficient proximal margin. A representative case is shown in Fig. 3. The proximal distance was estimated to be $5 \mathrm{~cm}$ from the cardia before ESD, which was performed without complications, but the resection was noncurative because of lymph vessel infiltration. Two months after ESD, the artificial ulcer scar caused fibrotic contraction, and the gastric resection was changed to TG. Local resection was performed in one patient because of an intraoperative finding of peritoneal metastasis. This patient was an 81-year-old woman with two EGCs. A preoperative computed tomography scan showed no lymph node metastasis. ESD was uneventful, and both lesions were resected en bloc with negative margins. Both lesions were undifferentiated type with a depth of pT1b and were positive for lymphatic infiltration with diameters of 8 and $15 \mathrm{~mm}$, respectively.

Among 23 patients in whom PPG with D1+ was the estimated gastric resection, the actual resection after ESD was PPG with D1+ in 17, DG with D1+ in 1, and DG with $\mathrm{D} 2$ in 5 . Among the 6 patients who underwent DG, 5 were in the noncurative category because of deep submucosal invasion with positive vertical margins. Therefore, DG with D2 was performed. The other patient underwent DG because the distal distance was shortened by fibrotic contraction after ESD (Fig. 4). For this patient, ESD was noncurative because of diffuse-type EGC with vascular infiltration. Although the estimated distance was $5 \mathrm{~cm}$ from the pylorus before ESD, the distance was shortened to $<3 \mathrm{~cm}$ after ESD.

Among 50 patients in whom proximal gastrectomy (PG) with $\mathrm{D} 1+$ was the estimated gastric resection, the actual resection after ESD was PG with D1 in 48 and TG with D2 in 2. In the 2 patients who underwent TG, ESD was noncurative because of deep submucosal invasion of lesions with positive vertical margins. Therefore, TG with D2 was performed.

Among 36 patients with deep submucosal invasion and positive/indefinite vertical margins, D2 was performed in 22; the other 14 underwent D1 because of advanced age or poor physical condition. Residual tumor was found in 9 (25\%) patients. The final pathological depth of the main tumor was pT1b in $26(72 \%)$ patients and pT2 or deeper in $10(28 \%)$. Lymph node metastasis was positive in 10 (28\%) of the 36 patients.

In total, altered gastric resection was performed in 4 $(1.6 \%)$ of the 255 patients because of fibrotic contraction 


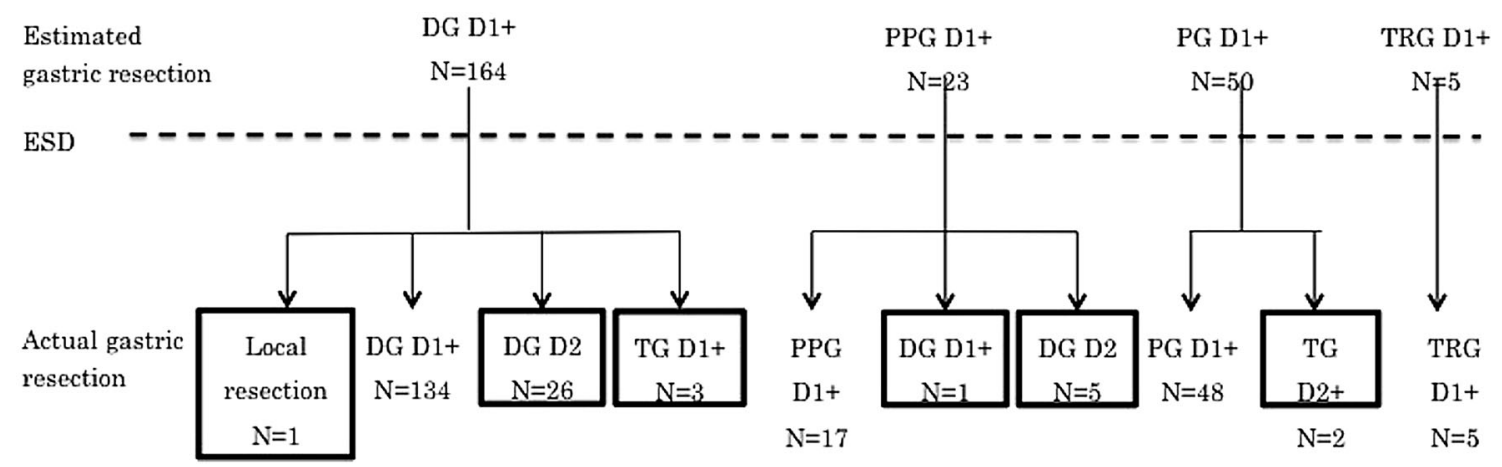

Fig. 2 Estimated gastric resection before endoscopic submucosal dissection (ESD) and actual resection performed after noncurative ESD. Patients undergoing surgery with modifications are indicated by

of the ESD scar. The lesion characteristics of these 4 patients are shown in Table 3. All specimens had cancerfree margins. The size of the resected specimen was large in comparison with the size of the lesion.

The extent of lymph node dissection was altered in $13 \%$ of the patients (33/255). In addition to the 22 patients with pT1b with positive/indefinite vertical margins, 1 patient with pT2 with a negative vertical margin, 7 patients with massive lymphovascular infiltration, and 3 patients with an intraoperative finding of suspected lymph node metastasis underwent $\mathrm{D} 2$ dissection.

\section{Discussion}

Because of the growing incidence of EGC in Japan, several minimally invasive surgical procedures have been developed, such as ESD, laparoscopic surgery, and PPG [11, 1416]. PPG has been reported as a safe and effective surgery in terms of nutritional advantage and a lower incidence of gallstone [17-19]. Better quality of life can be expected in patients who undergo these minimally invasive treatments compared with those who undergo TG with extensive lymphadenectomy. ESD is the most recent endoscopic resection technique capable of removing EGC lesions that fulfill particular conditions of negligible risk of lymph node metastasis; furthermore, it preserves the stomach at the same time. Because a precise diagnosis of the risk of lymph node metastasis is impossible before treatment, and to decrease the risk of overtreatment, ESD is sometimes used for diagnostic intent. Goto et al. [20] reported that ESD as a staging measure may not necessarily lead to a worse prognosis after additional gastrectomy in patients with EGC. Therefore, a substantial number of patients will be found to have undergone noncurative ESD on the basis of the histological findings of the resected specimen. squares. $D G$ distal gastrectomy, $P P G$ pylorus-preserving gastrectomy, $P G$ proximal gastrectomy, $T R G$ total remnant gastrectomy, $N$ number of patients

Because the lesions indicated for ESD are larger than those indicated for endoscopic mucosal resection (EMR), the surgical duration is often longer [21, 22] and the artificial ulcers that form after ESD tend to be larger [12]. Therefore, the effect of thermocoagulation is expected to be greater than that of EMR. A pathological study using gastrectomy specimens obtained by noncurative ESD reported that fibrosis was observed in the muscle layer proper or deeper [13]. Intraabdominal adhesions induced by ESD ulceration reportedly result in time-consuming procedures and greater blood loss during additional laparoscopic gastrectomy [23], whereas others have reported little to no influence on early postoperative outcomes [14, 15]. Tsujimoto et al. [15] reported no difference in operation duration and intraoperative blood loss between laparoscopic gastrectomy with or without preceding ESD. In our study, we experienced only one case of intraabdominal adhesion induced by ESD that required partial resection of the mesocolon. However, the influence of preceding ESD on additional gastric resection remains unclear.

The results of this study showed that alterations in gastric resection occurred in $1.6 \%$ of patients following noncurative ESD. Generally, gastrectomy with lymph node dissection should be performed for patients with submucosal invasion with or without margin involvement after noncurative ESD [24]. However, it remains unclear whether a modified resection technique such as PG or PPG with $\mathrm{D} 1$ or $\mathrm{D} 1+$ lymph node dissection is suitable for these patients. Therefore, in the current study, for patients with deep submucosal invasion with positive/indefinite vertical margins, the lesion depth was managed as cT2 and standard gastrectomy with D2 was performed. In fact, remnant cancer and/or lymph node metastasis was positive in $28 \%$ of the patients. Also, in these patients, preceding ESD altered the extent of lymph node dissection to a more extended dissection (D1+ to D2). 

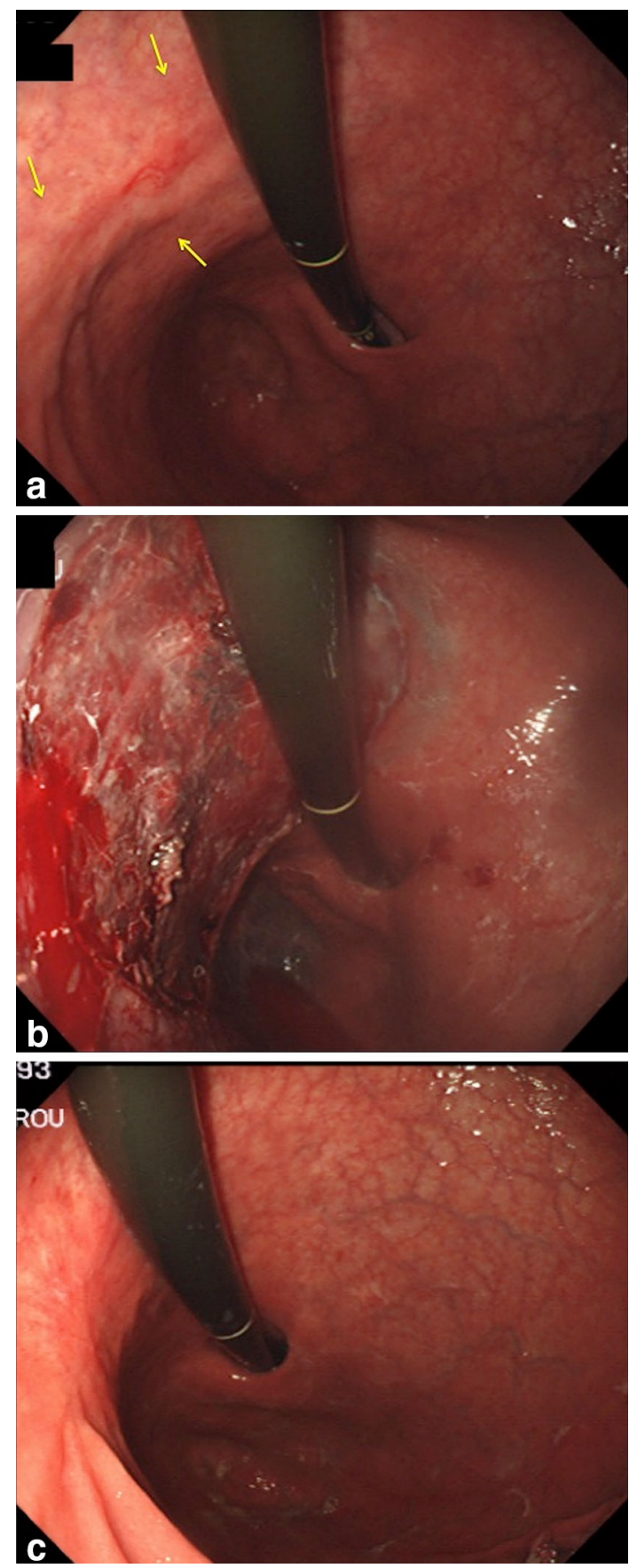

Fig. 3 Representative endoscopic images. a A 0-IIc cT1a(M) lesion (diameter, $20 \mathrm{~mm}$ ) on the lesser curvature of the upper body at an estimated proximal distance of $5 \mathrm{~cm}$. b An artificial ulcer that formed immediately after ESD. The proximal distance from the edge of the ESD ulcer has shortened to less than $5 \mathrm{~cm}$. c Two months after ESD. The proximal distance of the scar is nearly $2 \mathrm{~cm}$ from the cardia. Therefore, the estimated resection before ESD of DG was changed to TG

Our study included 43 patients with lesions preoperatively assessed as contraindication for ESD. The main reason for contraindication was the clinical depth of $\mathrm{T} 1 \mathrm{~b}$, and the reason to undergo ESD as an initial treatment included advanced age and desire of the patient. A total of 155 patients were diagnosed as pT1b or deeper from the result of ESD. The diagnostic sensitivity of submucosal invasion in our hospital is $73 \%$ [10], which is not inferior to that of previous reports [25]. It is particularly difficult to estimate the correct depth of lesions with ulceration findings. We aggressively perform diagnostic ESD for lesions of unknown depth to avoid surgery for lesions that could be treated by ESD. Therefore, a few lesions were diagnosed as pT2 by final pathological results. Improved diagnosis can avoid unnecessary ESD.

Although the resection margins were negative, DG or PPG as the estimated gastric resection had to be altered to TG (three patients) or DG (one patient) because of contraction of the ESD ulcer. The possibility of leaving a portion of the stomach was lost in these three patients because the resected ESD specimens were markedly larger than the tumors. Regardless, the resection line was determined by careful endoscopic observation to obtain sufficient tumor-negative margins. Large lesions of submucosal and undifferentiated-type cancers have been reported as risk factors for tumor-positive lateral margins after ESD [26]. Therefore, the resection line may have been set for a wide resection. Contraction is reportedly an important factor for the healing of large ESD ulcers [12, 13]. For lesions in which the surgical resection line comes near the cardia or pylorus ring, the surgeon must keep in mind that ESD will cause fibrotic contraction and shorten the distance from the cardia or pylorus.

Several limitations of this study must be addressed. First, the study was retrospective, and the gastric resection was retrospectively estimated on the basis of endoscopic images. In general practice, gastric resections are decided not only by the location of the lesion but also by patient age and physical condition, as well as the presence of hiatus hernia and the shape of the stomach. However, our study is unique because no previous study, to our knowledge, has investigated the influence of preceding ESD on additional gastric resections. Second, our stance on lesions with deep submucosal invasion with positive/indefinite vertical margins was to manage them as cT2, and standard gastrectomy with D2 was performed. However, the appropriate resection has not been established, and further studies are warranted.

In conclusion, $98.4 \%$ patients underwent scheduled gastric resection before $\mathrm{ESD}$, and the preceding gastric ESD had almost no influence on changing the gastric resection of the additional surgery. Although rare, the preceding ESD may necessitate alterations in gastric resection to widen the surgical area because of the contraction of lesions near the cardia or pylorus. 

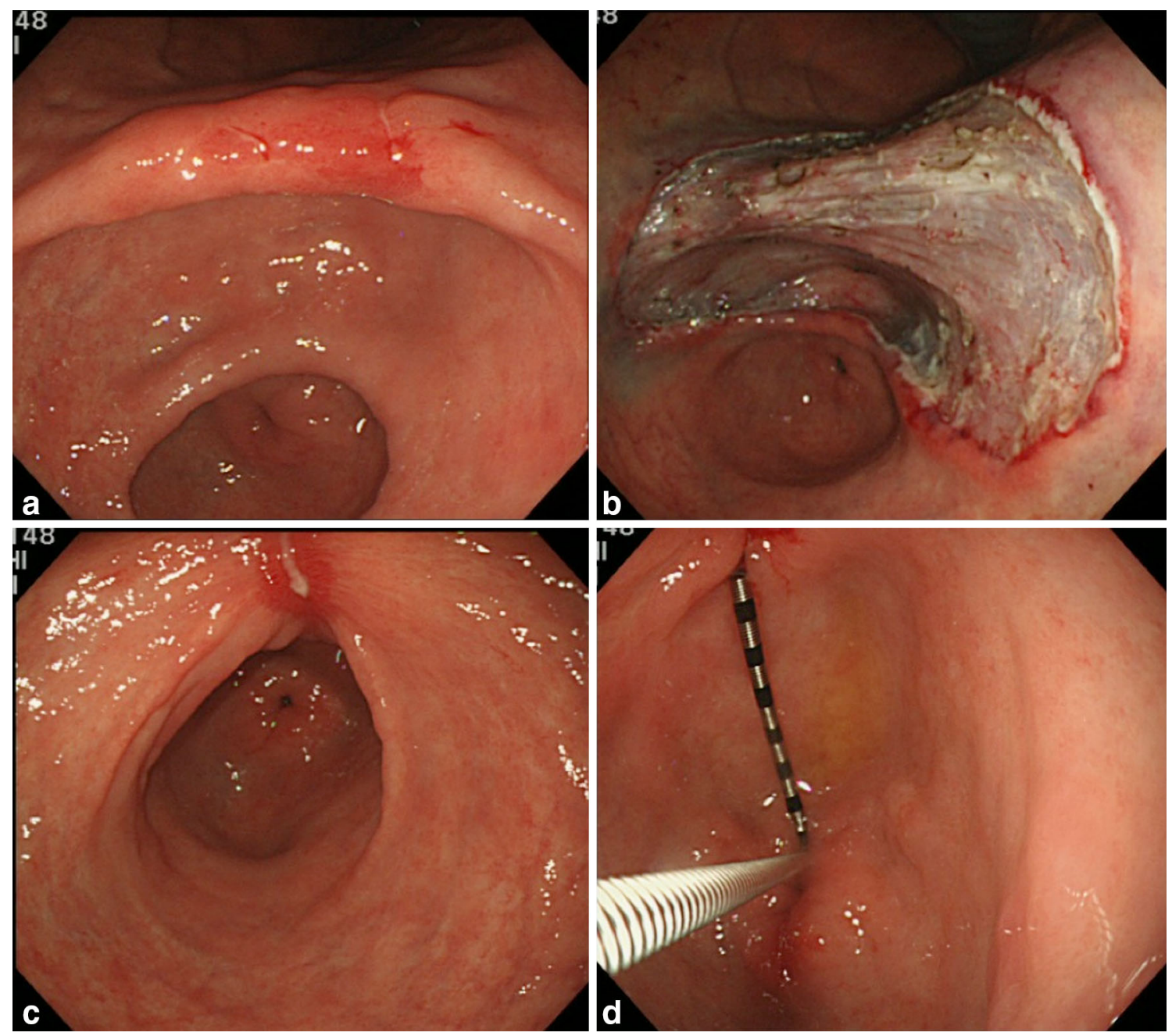

Fig. 4 Representative endoscopic images. a A 0-IIc lesion (diameter, $30 \mathrm{~mm}$ ) on the lesser curvature of the gastric angle. The distal margin from the pylorus is estimated at $4 \mathrm{~cm}$. b An artificial ulcer immediately after ESD. The distal distance from the edge of the ESD

ulcer to the pylorus is shortened. c, d Two months after ESD. The distal distance from the scar to the pylorus is less than $3 \mathrm{~cm}$. Therefore, the estimated resection before ESD of PPG was changed to DG

Table 3 Characteristics of four lesions with altered gastric resection resulting from fibrotic contraction after ESD

\begin{tabular}{lllllllllll}
\hline Loc & Circ & Type & Depth & Histology & Size of lesion $(\mathrm{mm})$ & UL & Margins & ly, v & Size of specimen (mm) & Alteration in surgical resection \\
\hline U & AW & 0-IIa & pSM2 & tub1 & 25 & - & negative & - & $50 \times 40$ & PG to TG \\
U & LC & 0-IIc & pSM2 & tub1 & 34 & - & negative + & $72 \times 36$ & PG to TG \\
U & PW & 0-IIc & pSM1 & tub1 & 24 & + & negative + & $51 \times 49$ & PG to TG \\
M & LC & 0-IIc & pSM1 & por & 30 & + & negative + & $62 \times 55$ & PPG to DG
\end{tabular}

Loc location, $U$ upper portion, $\operatorname{Circ}$ circumference, $A W$ anterior wall, $L C$ lesser curvature, $P W$ posterior wall, tubl well-differentiated adenocarcinoma, por poorly differentiated adenocarcinoma, $U L$ ulcerative findings, $l y$ lymph vessel infiltration, $v$ vascular infiltration, $P G$ proximal gastrectomy, $T G$ total gastrectomy, $P P G$ pylorus-preserving gastrectomy

\section{References}

1. Gotoda T, Yanagisawa A, Sasako M, Ono H, Nakanishi Y, Shimoda $\mathrm{T}$, et al. Incidence of lymph node metastasis from early gastric cancer: estimation with a large number of cases at two large centers. Gastric Cancer. 2000;3:219-25.
2. Hirasawa T, Gotoda T, Miyata S, Kato Y, Shimoda T, Taniguchi $\mathrm{H}$, et al. Incidence of lymph node metastasis and the feasibility of endoscopic resection for undifferentiated-type early gastric cancer. Gastric Cancer. 2009;12:148-52.

3. Kakushima N, Fujishiro M. Endoscopic submucosal dissection for gastrointestinal neoplasms. World J Gastroenterol. 2008;14:2962-7. 
4. Ono H, Hasuike N, Inui T, Takizawa K, Ikehara H, Yamaguchi R, et al. Usefulness of a novel electrosurgical knife, the insulationtipped diathermic knife-2, for endoscopic submucosal dissection of early gastric cancer. Gastric Cancer. 2008;11:47-52.

5. Tanaka M, Ono H, Hasuike N, Takizawa K. Endoscopic submucosal dissection of early gastric cancer. Digestion. 2008;77:23-8.

6. Kakushima N, Ono H, Tanaka M, Takizawa K, Yamaguchi Y, Matsubayash H. Endoscopic submucosal dissection using the insulated-tip knife. Tech Gastrointest Endosc. 2011;13:63-9.

7. Japanese Gastric Cancer Association. Japanese gastric cancer treatment guidelines 2010 (ver. 3). Gastric Cancer. 2011;14:113-23.

8. Oda I, Gotoda T, Sasako M, Sano T, Katai H, Fukagawa T, et al. Treatment strategy after non-curative endoscopic resection of early gastric cancer. Br J Surg. 2008;95:1495-500.

9. Kusano C, Iwasaki M, Kaltenbach T, Conlin A, Oda I, Gotoda T. Should elderly patients undergo additional surgery after noncurative endoscopic resection for early gastric cancer? Long-term comparative outcomes. Am J Gastroenterol. 2011;106:1064-9.

10. Kakushima N, Hagiwara T, Tanaka M, Sawai H, Kawata N, Takizawa K, et al. Endoscopic submucosal dissection for early gastric cancer in cases preoperatively contraindicated for endoscopic treatment. United European Gastroenterol J. 2013;1:453-60.

11. Hiki N, Nunobe S, Kubota T, Jiang X. Function-preserving gastrectomy for early gastric cancer. Ann Surg Oncol. 2013;20: 2683-92.

12. Kakushima N, Yahagi N, Fujishiro M, Iguchi M, Oka M, Kobayashi $\mathrm{K}$, et al. The healing process of gastric artificial ulcers after endoscopic submucosal dissection. Dig Endosc. 2004;16: 327-31.

13. Kakushima N, Fujishiro M, Kodashima S, Kobayashi K, Tateishi A, Iguchi $\mathrm{M}$, et al. Histopathologic characteristics of gastric ulcers created by endoscopic submucosal dissection. Endoscopy. 2006;38:412-5.

14. Jiang X, Hiki N, Yoshiba N, Nunobe S, Kumagai K, Sano T, et al. Laparoscopy-assisted gastrectomy in patients with previous endoscopic resection for early gastric cancer. Br J Surg. 2011;98: 385-90.

15. Tsujimoto H, Yaguchi Y, Kumano I, Takahata R, Matsumoto Y, Yoshida K. Laparoscopic gastrectomy after incomplete endoscopic resection for early gastric cancer. Oncol Rep. 2012;28: 2205-10.

16. Ono H, Kondo H, Gotoda T, Shirao K, Yamaguchi H, Saito D, et al. Endoscopic mucosal resection for treatment of early gastric cancer. Gut. 2001;48:225-9.
17. Jiang X, Hiki N, Nunobe S, Fukunaga T, Kumagai K, Nohara K, et al. Postoperative outcomes and complications after laparoscopy-assisted pylorus-preserving gastrectomy for early gastric cancer. Ann Surg. 2011;253:928-33.

18. Jiang X, Hiki N, Nunobe S, Fukunaga T, Kumagai K, Nohara K, et al. Long-term outcome and surgical with laparoscopy-assisted pylorus-preserving gastrectomy for early gastric cancer. Surg Endosc. 2011;25:1182-6.

19. Suh YS, Han DS, Kong SH, Kwon S, Chin CI, Kim WH, et al. Laparoscopy-assisted pylorus-preserving gastrectomy is better than laparoscopy-assisted distal gastrectomy for middle-third early gastric cancer. Ann Surg. 2014;259:485-93.

20. Goto O, Fujishiro M, Kakushima N, Kodashima S, Ono S, Yamaguchi $\mathrm{H}$, et al. Endoscopic submucosal dissection as a staging measure may not lead to worse prognosis in early gastric cancer patients with additional gastrectomy. Dig Liver Dis. 2008;40:293-7.

21. Cao Y, Liao C, Tan A, Gao Y, Mo Z, Gao F. Meta-analysis of endoscopic submucosal dissection versus endoscopic mucosal resection for tumors of the gastrointestinal tract. Endoscopy. 2009;41:751-7.

22. Park YM, Cho E, Kang HY, Kim JM. The effectiveness and safety of endoscopic submucosal dissection compared with endoscopic mucosal resection for early gastric cancer: a systematic review and metaanalysis. Surg Endosc. 2011;25:2666-77.

23. Akagi T, Shiraishi N, Hiroishi K, Etoh T, Yasuda K, Kitano S. Case series of intra-abdominal adhesions induced by artificial ulceration after endoscopic submucosal dissection before additional laparoscopic gastrectomy. Gastrointest Endosc. 2010;72: $438-43$.

24. Song KY, Hyung WJ, Kim HH, Han SU, Cho GS, Ryu SW, et al. Is gastrectomy mandatory for all residual or recurrent gastric cancer following endoscopic resection? A large-scale Korean multi-center study. J Surg Oncol. 2008;98:6-10.

25. Ono H, Yoshida S. Endoscopic diagnosis of the depth of cancer invasion for gastric cancer. Stomach Intest. 2001;3:334-40 (in Japanese with English abstract).

26. Kakushima N, Ono H, Tanaka M, Takizawa K, Yamaguchi Y, Matsubayashi $\mathrm{H}$. Factors related to lateral margin positivity for cancer in gastric specimens of endoscopic submucosal dissection. Dig Endosc. 2011;23:227-32. 